\section{Representação Política e de Interesses: bases associativas dos deputados federais de 1999-2007}

Odaci Luiz Coradini ${ }^{1}$

Resumo: O texto resulta de um trabalho centrado na análise do engajamento associativo no recrutamento e legitimação de elites políticas. Tomando os deputados federais que assumiram no período de 1999 a 2007, são examinadas as diferentes modalidades de relações com sindicatos e associações. Essas relações são confrontadas com outras condições e recursos presentes nos respectivos trajetos, tais como aqueles ligados à titulação escolar, ao montante do patrimônio econômico, à filiação partidária e à quantidade de mudanças de partido político. Conforme uma das conclusões gerais, ocorre uma forte homologia entre a distribuição dos deputados conforme suas vinculações associativas, na política partidária e no espaço político. Porém, não se trata apenas de alguma dicotomia entre esferas de atividades, associativas e político-partidárias, mas de diferentes padrões de complementaridade, afinidades eletivas, ambivalências e de distanciamento e, portanto, de recursos e modalidades que podem ser utilizadas em diferentes condições e processos de politização.

Palavras-chave: Representação Política, Capital Associativo, Elites Políticas, Engajamento Político e Militância, Grupos de lanteresse

\section{Apresentação}

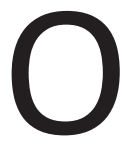
principal problema abordado no presente texto consiste nas relações entre recursos decorrentes de engajamento associativo e ocupação de cargos políticos. Mais especificamente, trata-se de um esforço no sentido de apreender algumas das bases da reconversão de capital associativo (GAXIE \& OFFERLÉ, 1985) em trunfos eleitorais e conquista do cargo de deputado federal no Brasil no período recente.

Em trabalho anterior (CORADINI, 2007), perseguimos a hipótese de que, na constituição do espaço de representação política, a gama de princípios e critérios de classificação e de recrutamento da elite política, dependente de processos
Recebimento:

15.09.2009

Aprovado:

26.01.2011

1. Doutor em Antropologia Social pelo

Museu Nacional/ Universidade Federal do Rio de Janeiro (UFRJ); Professor da Universidade Federal do Rio Grande do Sul (UFRGS). Atualmente, dedicado ao estudo, particularmente, dos processos de recrutamento de elites políticas e culturais e das transformações no ensino universitário. As últimas publicações incluem:

- CORADINI, O. L. (2007), Associative/Union Commitement and the recruitment of political elites: recent trends in Brazil, International Journal of Contemporary Sociology, vol. 44, n. 2, p. 201-227

- CORADINI, O. L. (2005), Formation et insertion professionnelles des prefesseurs de sciences humaines et sociales au Rio Grande do Sul, Cahiers du Brésil Contemporain, n. 57/58-5960 , p. 223-259 e-mail: coradini@ ufrgs.br 
2. Para um estudo comparativo dos parlamentares da maior parte dos países europeus, com ênfase na "profissionalização" da carreira política e nos condicionantes em seu recrutamento, pode ser consultado Best \& Cotta (2000).

3. Foram incluídas as seguintes modalidades de associações/ sindicatos ou organização de interesses: 1) associações/sindicatos de empresários; 2) associações/ sindicatos de trabaIhadores urbanos, rurais e de funcionários públicos; 3) associações/sindicatos de médicos, advogados, engenheiros e assemelhados; 4) associações/ sindicatos de professores (de todos os níveis em conjunto); 5) associações de moradores, assistenciais e de defesa de "direitos" de "cidadania"; 6) organizações do movimento estudantil; 7) clubes esportivos e assemelhados; 8) associações/organizações de prefeitos, vereadores, municípios e assemelhadas. eleitorais, deveria ser analisada considerando as condições de possibilidade na reconversão de categorias e recursos presentes na organização e representação de interesses em recursos eleitoral e politicamente consideráveis. Nas condições históricas concretas em foco, ou seja, estruturas sociais e políticas "periféricas", isso pode sofrer os efeitos do fato de que os partidos políticos não detêm o monopólio da formulação e nem da agregação de posições políticas e de representação de interesses. Porém, para além dessas particularidades das condições "periféricas", que têm o efeito de tornar mais salientes determinados aspectos dos processos eleitorais e políticos, é pressuposto que a heterogeneidade de princípios e critérios de avaliação nas relações com e na estruturação do espaço político é constitutiva da representação política.

Essa heterogeneidade das condições da estruturação do espaço de representação política abrange, inclusive, os padrões de relacionamento entre o engajamento e militância associativa ou de outra natureza com o engajamento partidário e as disputas eleitorais. Sendo assim, por um lado, particularmente em alguns países centrais, como é o caso da França, a consolidação do espaço político pode reforçar o monopólio do engajamento e militância partidária (GAXIE \& OFFERLÉ, 2005), além de outras tendências correlatas, em detrimento do engajamento associativo, embora isso não se aplique do mesmo modo ao conjunto dos países europeus ${ }^{2}$. Por outro lado, em condições como as do Brasil, como tentamos demonstrar num trabalho que inclui o conjunto dos ministros, senadores e deputados federais do período de 1994 a 2002 (CORADINI, 2007), o aumento da concorrência eleitoral com o fim do regime autoritário teve o efeito de aumentar constantemente a proporção de eleitos ou de nomeados como ministros, com algum tipo de vinculação com organizações de representação de interesses.

No presente texto, interessa circunscrever o enfoque aos deputados federais, visto que, como concorrentes bem sucedidos para um mesmo tipo de cargo, oferecem condições para o exame mais aprofundado de alguns padrões vigentes na reconversão de diferentes espécies de recursos em recursos eleitorais e ocupação desse tipo de cargo. A base empírica inclui o total de 1.167 deputados federais que assumiram o cargo nas legislaturas de 1999 a 2003, de 2004 a 2006 e de 2007 a 2011.

Se, ao tomar o conjunto dos ministros, senadores e deputados federais no período imediatamente anterior, de 1994 a 2002, foi constatado o aumento crescente na proporção de algum tipo de político com algum vínculo com associações/sindicatos, para os deputados federais que assumiram o cargo no período de 2003 a 2011, foi constatada certa estabilidade nessa proporção. De um total de 38,98\% que não menciona qualquer vínculo com organizações associativo-sindicais ou de outro tipo ${ }^{3}$, na legislatura subsequente, de 2003 
a 2007, ocorre algo praticamente idêntico, e um pequeno acréscimo desses sem qualquer vínculo declarado (43,33\%) na última legislatura, iniciada em 2007. A composição final desta última, no entanto, não é definitiva, visto que o critério adotado foi o de incluir todos os deputados que assumiram o cargo e, para essa última legislatura, ainda resta a maior parte do período, no qual muitos podem ser substituídos ${ }^{4}$. Em todo caso, isso não parece ter maiores efeitos na composição do universo estudado e a conclusão geral que parece evidente é a de que, apesar de abranger a maior parte dos deputados federais, o aumento daqueles que apresentam algum vínculo com organizações de representação de interesses não é ilimitado.

Por outro lado, essas modalidades de vinculação com associações, sindicatos e outras organizações de interesse não têm qualquer pretensão de exaustão das relações prévias dos deputados em pauta com interesses organizados e com redes de interdependência. Algumas das outras modalidades de organização de interesses e redes podem ter um caráter mais corporado e formalizado, ao passo que outras estão baseadas em universos aparentemente "externos" às atividades políticas. Por exemplo, ao examinar os trajetos sintetizados nas biografias dos deputados, fica evidente o forte peso daqueles com alguma posição de destaque em determinadas igrejas. De modo semelhante, para parte considerável dos mesmos, tanto na entrada, como na carreira política, as relações de parentesco com outros políticos são decisivas. Para mencionar apenas mais um tipo de recurso não contemplado diretamente nessa análise, para a maior parte desses deputados a respectiva posição nas relações centro/periferia e suas manifestações geográficas são decisivas na configuração das chances de recrutamento e na carreira política, mas, a exemplo dos demais recursos, sempre tendo efeitos em combinação com outras modalidades de recursos.

A exemplo da relativa estabilidade na proporção daqueles com vínculos com algum tipo de associação, sua distribuição entre as diferentes categorias também não sofre maiores alterações no período considerado, seja no que tange àqueles com vínculos com associações/sindicatos de empresários (13,25\% para o período de 1999 a 2003, outros 11,83\% em 2003/2007 e 10,00\% dos que assumiram em 2007); com as associações/sindicatos de trabalhadores urbanos, rurais e de funcionários públicos (oscilando entre onze a doze por cento), associações/sindicatos de médicos, advogados, engenheiros e assemelhados (sempre em torno de doze por cento); associações/sindicatos de professores - de todos os níveis tomados em conjunto (entre pouco mais de dois e pouco mais de três por cento); associações de moradores, assistenciais e de defesa de "direitos" de "cidadania" (entre pouco mais de sete e oito por cento); os que tiveram engajamento somente em organizações do movimento estudantil (ente cinco e pouco mais de seis por cento); os vinculados a clubes esportivos e assemelhados
4. Como foram incluídos todos os deputados que assumiram o cargo, inclusive os que foram eleitos como suplentes, apesar de 530 vagas formais, na legislatura de 1999 a 2003 foi constatado um total de 649 indivíduos, naquela de 2003 a 2007 outros $631 \mathrm{e}$, por fim, na legislatura de 2007 a 2011 foram incluídos 510 casos com informações suficientes disponíveis. Portanto, nesse último caso há uma quantidade menor que os 530 formalmente eleitos. Deve-se considerar ainda que o levantamento foi feito em meados de 2007, portanto, antes do período de candidaturas paras as eleições municipais, nas quais muitos deputados se candidataram, sendo, então, substituídos pelos respectivos suplentes. 
5. No caso de um mesmo indivíduo ter tido engajamento em mais de uma modalidade foi considerada somente aquela com maior peso em seu trajeto. (entre dois e pouco mais de meio por cento); e, por fim, os de organizações que congregam políticos ocupantes de cargos - prefeitos, vereadores, municípios, regiões, dentre outras (oscilando entre pouco mais de quatro e seis por cento) ${ }^{5}$.

De modo semelhante, no que tange às posições ocupadas na respectiva organização, há uma relativa estabilidade. Os que foram dirigentes em âmbito nacional oscilam entre pouco menos de oito e onze por cento; enquanto os dirigentes em nível estadual, em todo o período considerado, representam cerca de uma quarta parte; os de âmbito municipal, entre pouco mais de cinco e oito por cento, de modo semelhante aos cujo cargo ocupado é regional e, inclusive, aqueles que foram dirigentes de organizações cuja hierarquia não tem base territorial. Os que são apenas membros ou sócios se mantêm em torno de cinco por cento (4,93\% em 1999/2003, 5,68\% em 2003/2007 e 5,10\% em 2007/2011), além dos que não declaram algum vínculo com esse tipo de organização (os já mencionados 38,83\% em 1999/2003, 39,14\% em 2003/2007 e 43,14\% em 2007/2011).

Como boa parte dos deputados se mantém por mais de uma legislatura, são considerados mais de uma vez na análise. Isso, no entanto, não chega a ter efeitos consideráveis nos resultados. Ou seja, a proporção daqueles que participam de apenas uma legislatura e dos que são reeleitos como deputados federais, no que tange à vinculação com as associações/sindicatos em consideração, são muito semelhantes. Tomando apenas os que não declaram qualquer vínculo com as organizações consideradas, para aqueles que participam apenas da legislatura de 1999/2003 (desprezando-se as anteriores), a proporção é de 41,04\%, muito próxima dos que participaram da legislatura de 1999/2003 e também daquela de $2007 / 2011$ (44,44\%). Algo semelhante ocorre com os que participaram da legislatura de 1999/2003 e também das duas subsequentes (37,01\%) ou, então, apenas das duas últimas, de 2003/2007 e 2007/2011 (41,48\%). O único conjunto que se afasta consideravelmente da média são os que participaram somente da legislatura de 2003 a 2007 (apenas vinte indivíduos), com mais da metade $(57,1 \%)$ sem qualquer vínculo com as organizações consideradas.

\section{Recursos sociais e representação política}

Mesmo análises centradas na regras e princípios da representação política moderna e, portanto, não nos recursos e interesses em jogo nesse tipo de processo, como as de Manin (1989), observam que se trata de algo que envolve diferentes lógicas e dinâmicas sociais e de espécies de recursos sociais em confronto. Na chamada "democracia dos partidos", o voto constitui um meio de expressão de uma identidade e "a representação se torna sobretudo o reflexo da estrutura social" (MANIN, 1989, p. 268-269). Na perspectiva do presente trabalho, 
no entanto, essa expressão de identidade e de interesses não é, necessariamente, redutível à sua expressão partidária6.

Proposições como aquela de Dalloz (2003, p. 2-8) no sentido de considerar a representação política como estando, simultaneamente, baseada na busca de "distinção" e de "identificação" com os representados, podem proporcionar novas perspectivas de abordagem. Porém, no grau de generalidade que estas proposições se mantêm, tomando para análise apenas princípios de classificação mais difusos, embora em confronto com outras configurações nacionais, mas não nos processos eleitorais concretos, tornam difícil a apreensão mais aprofundada desses princípios e recursos em confronto. Mas há uma outra dimensão destacada por Dalloz (2003, p.2) e, inclusive, Offerlé (1998), baseada em trabalhos de Bourdieu (1984), que pode significar um grande avanço. Trata-se dos efeitos da representação na própria constituição dos interesses e categorias representadas. Sendo assim, a antinomia entre a ação política através do grupo constituído ou a expressão solitária da opinião previamente formada através do voto (BOURDIEU, 2000, p. 81-91) está mais diretamente relacionada com o voto e não com os processos eleitorais.

Por outro lado, esses efeitos e os problemas analíticos correlatos devem ser confrontados com os processos de "politização", no sentido definido por Lagroye (2002, p. 360). Trata-se de uma "requalificação das atividades sociais as mais diversas que resulta de um acordo prático entre agentes sociais inclinados, por múltiplas razões, a transgredir ou a por em questão a diferenciação dos espaços de atividades".

Essas proposições devem ser destacadas, inclusive, porque a maior parte dos modelos analíticos, de algum modo, deriva do chamado modelo "pluralista". Para o que está em pauta, é necessário enfatizar, em primeiro lugar, que o "pluralismo" tem como base uma experiência histórica e política específica. Algo semelhante ocorre com o chamado modelo "corporativista" ou o "necorporativista", que consiste na abstração e generalização de determinados aspectos de condições históricas específicas, embora, nesse caso, com menores pretensões de universalização de sua capacidade heurística. Nas palavras de Offerlé (1998, p. 144), trata-se do problema do alto grau de generalidade que esse tipo de análise adquiriu, sem dar maior importância à constituição dos atores eficientes, além da proeminência atribuída aos grupos institucionalizados. Isso fica evidente, inclusive, nos confrontos desses "modelos", como entre Wilson $(1982,1983)$ e Keeler (1985) relativamente ao caso francês, cuja principal questão, ou seja, a maior adequação ao "pluralismo" ou então ao "corporativismo", tem como base uma postura deducionista ancorada em um ou outro desses "modelos".

Um outro ponto relativamente ao modelo "pluralista" a ser destacado para
6. Para algumas discussões mais recentes sobre as relações entre mobilizações e movimentos sociais e partidos políticos, ver, particularmente, Goldstone (2003), Jankins \& Kladermans (1995) e Combes (2004). 
7. Uma das sínteses mais representativas e permanentes dessa perspectiva, para a qual o "sistema políticos e grupos de interesse estão rigidamente diferenciados", encontra-se em Almond (1958, p. 275 , passim).
8. Sistema de ação, no caso, como "conjunto de agrupamentos e de associações que contribuem (...) para a construção de um grupo de referência" (Lagroye, François \& Sawicki, 2002, p. 271). o que está em pauta vincula-se às suas premissas quanto aos processos de politização. Como generalização de determinadas condições históricas concretas fortemente calcadas na competição entre grupos de interesses específicos, é pressuposta a formulação e organização de interesses nesse âmbito, tido como não diretamente político (a "sociedade civil"), para a posterior agregação pelos partidos políticos e sua inclusão nos processos decisórios e nas políticas governamentais. Ou seja, trata-se de um esquema com um pólo no "mercado" ou em organizações da "sociedade civil" calcado na competição e outro na "política", com sentido de eleitoral, partidário ou governamental”.

Mesmo sem entrar aqui nos problemas de fundo que todo "modelo" decorrente da generalização de determinadas condições históricas e políticas específicas pode implicar, inclusive, o normativismo e o prescritivismo; para o que está em pauta, o mais importante é destacar que, nas condições estudadas, se trata de condições "periféricas" e, portanto, com determinadas particularidades que incluem os processos de politização. Embora não se disponha de esquemas que consigam ir além de um forte grau de generalidade, há um relativo consenso quanto alguns pontos, dentre os quais, o peso do neopatrimonialismo que tende a ocorrer nas sociedades de descolonização recente ou de capitalismo tardio. Ou seja, nos países do Terceiro Mundo, a prática neopatrimonial tende a reforçar os recursos dos grupos no poder político, mas também as trocas com os melhor posicionados, tais como notáveis, sindicalistas e formadores de opinião. Por outro lado, essa abordagem, sem as devidas contextualizações, pode levar a "construções transculturais", a exemplo do desenvolvimentismo (BADIE, 1994, p. 191-192). Em segundo lugar, há um relativo consenso também quanto à importância central dos recursos políticos detidos por determinadas elites. Diversamente dos países de capitalismo central, onde os processos de recrutamento de novas elites e de formação e organização de interesses estão diretamente associados às transformações ocorridas na esfera econômica, nas sociedades "periféricas", o recrutamento das elites políticas tem um caráter mais "político" ou "técnico" (BADIE, 1994, p. 111-133). Isso, no entanto, não se aplica de modo homogêneo e no mesmo grau às diferentes condições concretas, que tendem a abarcar, de modo interdependente, tanto situações mais "burguesas" como neopatrimonialistas.

Como os dados empíricos expostos a seguir indicam, alguns processos de definição e representação de interesses já emergem de um modo mais politicista, como determinado sindicalismo associado a sistemas de ação mais afins ${ }^{8}$. Por outro lado, outros interesses, apesar de fortemente organizados, mantêm outras modalidades de relacionamento com o espaço político. Isso inclui tanto as pressões através de organizações que se pretendem "externas" ao universo das atividades políticas, como certo tipo de lobismo em nome de categorias 
profissionais ou de setores empresariais, como aquelas cuja ação pretende se ater à pressão direta sobre os processos decisórios e à implementação de políticas governamentais.

Isso se manifesta de modo mais direto nas modalidades de organização de interesses e em suas relações com os representantes políticos. Tomando, através de alguns indicadores básicos, relativos às principais dimensões em pauta (econômica, profissional, partidária), um primeiro eixo de oposição entre os deputados estudados está centrado particularmente na filiação partidária e no número de filiações, nas ocupações efetivamente exercidas no trajeto profissional e na formação escolar. Como as classificações profissionais apresentam uma ampla série de problemas e limitações em seu uso sociológico, por razões mais gerais e também por se tratar de "profissionais" da política em condições "periféricas", além da autoclassificação, foram tomadas as principais ocupações efetivas no decorrer da carreira, com base na biografia (que permite, inclusive, dispor de uma aproximação da quantidade de tempo dedicado a cada atividade). No primeiro pólo desse eixo ${ }^{9}$, situam-se os filiados ao PT (Partido dos Trabalhadores) e ao PCdoB (Partido Comunista do Brasil), com apenas uma filiação em seu percurso, predominantemente professores de diferentes graus de ensino e trabaIhadores da produção de bens e do comércio e prestação de serviços. Em termos de formação escolar, predominam os formados em algum curso das chamadas ciências humanas (ciências sociais, pedagogia, letras, filosofia, psicologia, teologia e comunicação social) ou, então, aqueles sem curso universitário. Quanto ao patrimônio, estão mais diretamente associados às faixas de cinquenta a quinhentos mil dólares; no que tange ao tipo de engajamento associativo/sindical, a esse pólo corresponde mais diretamente os vinculados às associações/sindicatos de professores (de todos os níveis) e de trabalhadores urbanos, rurais e de funcionários públicos. No pólo oposto desse mesmo eixo, se destacam os filiados ao DEM/PFL (Partido da Frente Liberal/Democratas $)^{10} \mathrm{e}$, em menor grau, ao PP (Partido Progressista), PMDB (Partido do Movimento Democrático Brasileiro), PL (Partido Liberal) e ao PSDB (Partido da Social-Democracia Brasileira), com três a cinco filiações. Quanto ao montante do patrimônio econômico, as faixas mais diretamente associadas a esse pólo são as mais altas (de mais de um milhão de dólares), como principal ocupação na carreira profissional, a administração/propriedade de empresas privadas e, quanto ao curso universitário, a graduação em direito. No que tange à modalidade de engajamento associativo, a esse pólo correspondem as associações/sindicatos de empresários e, em menor grau, os clubes esportivos e assemelhados e as organizações de prefeitos, vereadores ou políticos em geral.

Um segundo pólo de oposição que se destaca está baseado, particularmente, na filiação partidária, nas principais ocupações na carreira profissional e na
9. Como uma primeira aproximação, foi aplicado um teste de análise de correspondência múltipla tomando como variáveis ativas as que seguem: principais ocupações no decorrer da carreira profissional, curso escolar mais alto (até a graduação universitária), montante do patrimônio econômico, filiação partidária atual e o número de filiações partidárias no trajeto político. Como variáveis ilustrativas foram incluídas o tipo de engajamento associativo/ sindical predominante no trajeto $\mathrm{e}$ a posição ocupada na respectiva organização.

10. Como a transformação recente do PFL no DEM foi meramente nominal, foram considerados como um mesmo partido. 
titulação escolar. Nesse segundo eixo, um pólo é constituído mais diretamente por aqueles cuja carreira é composta pelo exercício da medicina e a ocupação de cargos públicos por indicação ou eletivos, predominantemente formados em medicina, filiados em diferentes partidos, como o PSB, PDT, PCdoB e o PSDB, dentre outros pequenos partidos, geralmente com três filiações partidárias no percurso, com patrimônio concentrado nas faixas de cem a quinhentos mil dólares. A esse pólo correspondem mais diretamente as associações/sindicatos de médicos, advogados, engenheiros e assemelhados. No pólo oposto, nesse mesmo eixo, se destacam os administradores/proprietários de empresas, com mais de um milhão de dólares de patrimônio declarado, filiados particularmente ao DEM/PFL ou ao PP, mais frequentemente com quatro filiações partidárias durante o respectivo trajeto, formados particularmente em direito.

\section{Relações com associações/sindicatos e com a esfera política}

Um dos aspectos que mais diferenciam os deputados que participam das diferentes modalidades de associações/sindicatos são as relações diferenciadas com o universo da "política", no sentido amplo. Apesar de se tratar de um conjunto de deputados e cujos trajetos, portanto, os caracterizam como "empresários" das atividades políticas, o significado e as modalidades de influenciar a ocupação de cargos e a distribuição de recursos públicos são distintos. Sendo assim, não é surpreendente que, tendo em consideração aqueles indicadores utilizados acima, os deputados que mantêm vínculos com as associações/sindicatos de empresários se assemelham, em muitos aspectos, aos que não mantêm qualquer engajamento associativo/sindical, embora os diferencie em outros aspectos. Isso porque, no que tange às principais dimensões consideradas (tais como ocupações profissionais, patrimônio econômico, titulação escolar e filiação partidária), os deputados vinculados a associações/sindicatos de empresários apresentam trajetos e posições mais próximas do universo empresarial ou de atividades privadas em geral. Essas atividades políticas têm um caráter de menor associação com ideologias e cargos estatais e mais de defesa de interesses e regras para esse universo, o que não exclui, mas pode ser complementar com outras "causas" mais gerais ou difusas, com as quais pode haver diferentes afinidades seletivas.

As características próprias abrangem tanto os respectivos trajetos sociais e políticos como as posições e "causas" defendidas. No que tange à profissão declarada (em nove agrupamentos), a maior parte (55,7\% contra $23,7 \%$ do conjunto do universo) dos vinculados a associações/sindicatos de empresários classifica-se em alguma categoria de proprietários de diferentes setores ou de altos funcionários de empresas privadas; quase uma quinta parte $(18,3 \%)$ como 
outros profissionais com titulação universitária, que não médicos ou advogados; uma décima parte $(9,9 \%)$ como advogados; e os poucos restantes em outras categorias. Quanto aos sem qualquer vínculo associativo declarado, quase uma quinta parte $(17,1 \%)$ é proprietária de diferentes setores ou são altos funcionários de empresas privadas; também quase uma quinta parte $(17,3 \%)$ de outros profissionais com titulação universitária que não médicos e advogados; uma proporção próxima $(19,0 \%)$ de advogados; uma décima parte $(10,3 \%)$ de professores (de todos os níveis); e um pouco menos de médicos (7,3\%) e de jornalistas, radialistas e produtores de espetáculos (7,1\%). Ao tomar, não pelas classificações com base nas próprias declarações nas biografias, mas pelas classificações dos censos, os resultados são muito semelhantes. Nesse caso, mais da metade (58,0\% contra $23,4 \%$ do conjunto do universo) dos vinculados a associações/ sindicatos de empresários são proprietários e diretores de empresas ou organizações privadas; uma parte considerável $(14,5 \%)$ de profissionais das ciências exatas - ou seja, particularmente engenheiros; outro tanto de profissionais das ciências jurídicas (9,9\%); e a pequena quantidade restante em outras categorias. Por sua vez, aqueles sem qualquer vínculo associativo/sindical mantêm uma quarta parte $(26,7 \%$ contra $23,4 \%$ do conjunto do universo) de proprietários e diretores de empresas ou organizações privadas; e uma proporção mais elevada $(19,8 \%)$ de profissionais das ciências jurídicas; outra parte menor de profissionais das ciências exatas $(7,5 \%)$ e de membros do poder público $(4,5 \%)$.

Quanto às principais ocupações durante a carreira profissional, também, apesar de algumas diferenças significativas entre os vinculados a associações/sindicatos de empresários e aqueles sem vínculos associativos declarados, ocorrem algumas fortes diferenças. Apesar da relativa dispersão, a maior concentração daqueles com vínculos em associações/sindicatos de empresários, com mais de uma quinta parte $(21,5 \%$ contra $7,0 \%$ do conjunto do universo), ocorre entre aqueles cujo trajeto está centrado na combinação da administração/propriedade de empresas privadas; com a ocupação de cargos públicos por indicação; na administração/propriedade de empresas privadas com cargos públicos eletivos ( $20,8 \%$ contra $6,3 \%$ do conjunto do universo); simplesmente como administrador/proprietário de empresas privadas ( $13,8 \%$ contra $6,7 \%$ do conjunto do universo); e na administração/propriedade de empresas privadas com a ocupação de cargos públicos por indicação e eletivos (10,0\% contra 4,5\% do conjunto do universo), e os poucos restantes se distribuem em várias outras categorias. Em síntese, de modo geral, trata-se de trajetos profissionais centrados na administração/propriedade de empresas e no exercício de cargos públicos, seja por indicação ou por eleição. Alguns apresentam um caráter mais empresarial e privatista, sendo que os cargos políticos, via de regra, são justapostos à condição de empresário. Outros estão mais centrados na ocupação de cargos públicos, para os quais o universo empresarial tem mais um sentido de condição social de 
origem e fonte de recursos, além de referência para a formulação e defesa de interesses e fonte de recursos, e menos de exercício profissional ou de gestão.

No que tange ao montante do patrimônio econômico, também há muita semeIhança entre os vinculados a associações/sindicatos empresariais e aqueles que não declaram qualquer vínculo associativo. Porém, há uma nítida maior proporção dos vinculados a associações/sindicatos de empresários nas faixas mais altas. Uma terça parte dos mesmos (33,6\% contra $13,3 \%$ do conjunto do universo) situa-se na faixa de um milhão de dólares ou mais e quase todo o restante acima de cem mil dólares; enquanto apenas pouco mais da décima parte $(13,1 \%)$ dos sem vínculos associativos e a mesma proporção do conjunto do universo se mantém nessa faixa. Uma terça parte $(34,9 \%)$ dos sem qualquer vínculo associativo situa-se na faixa de cem a quinhentos mil dólares.

No que tange ao curso do título escolar mais elevado, também os deputados vinculados a associações/sindicatos de empresários apresentam determinadas características muito próprias. A principal associação ocorre com os cursos de engenharia, com mais de uma quinta parte $(22,3 \%$ contra $9,8 \%$ do conjunto do universo), e de direito que também inclui mais de uma quinta parte $(22,3 \%$ contra $9,8 \%$ do conjunto do universo), se bem que no que no curso de direito essa proporção seja menor que a média do conjunto dos deputados. Outras concentrações significativas para os vinculados a associações/sindicatos de empresários ocorrem com o curso de administração (9,2\%), agronomia (5,4\%) e economia (6,2\%). Apesar da quantidade significativa de formados em medicina ( $7,7 \%$ contra $13,1 \%$ do conjunto do universo), esta é bem menor que a média do conjunto dos deputados. Além disso, uma parte significativa, embora próxima da média geral, desses vinculados a associações/sindicatos de empresários $(17,7 \%)$ não têm qualquer curso superior. Comparativamente, os sem qualquer vínculo associativo declarado, no que tange à titulação escolar, apesar da forte semelhança com os vinculados a associações/sindicatos de empresários, apresentam uma concentração ainda maior de formados em direito, com uma terça parte $(32,4 \%)$ e também daqueles sem qualquer curso superior $(19,3 \%)$, o restante se distribuindo de modo esparso entre diferentes cursos.

Como já mencionado, um dos principais diferenciadores dos vinculados a associações/sindicatos de empresários relaciona-se à filiação partidária. Mais de uma quinta parte (22,9\% contra $13,0 \%$ do conjunto do universo) é filiada ao PFL/ DEM; outro tanto, embora nem sempre acima da média, ao PSDB (16,8\% contra $13,9 \%$ do conjunto do universo), PTB (Partido Trabalhista Brasileiro - 9,2\% contra $7,2 \%$ do conjunto do universo), PP $(13,0 \%$ contra $6,3 \%$ do conjunto do universo), PMDB (16,0\% contra 16,9\% do conjunto do universo), PL (9,2\% contra $4,5 \%$ do conjunto do universo), dentre outros em menor grau. Quanto a esse 
ponto, os deputados sem qualquer vinculação associativa apresentam um menor grau de concentração, com distribuição esparsa em quase todos os partidos.

Esse padrão de filiação partidária tem fortes implicações na rotatividade e, portanto, na quantidade de trocas de partido. Mais de uma quinta parte $(23,7 \%$ contra $16,8 \%$ do conjunto do universo) dos deputados vinculados a associações/ sindicatos de empresários teve três filiações, e outro tanto $(22,1 \%)$, uma proporção muito mais alta que o conjunto dos deputados (6,9\% contra $4,3 \%$ do conjunto do universo), teve seis, sete ou mais filiações (3,8\%). Mas, apesar dessa alta proporção daqueles com várias mudanças de partido, aqueles sem qualquer vínculo associativo, bem como os vinculados a associações de prefeitos, vereadores, municípios e assemelhados os superam nesse aspecto.

Uma outra forma de examinar as relações entre o pertencimento a associações/sindicatos de empresários e posições políticas, além da filiação partidária, é através da participação em frentes parlamentares. Ao tomar o total de 148 frentes parlamentares existentes na legislatura de 2003 a $2007^{11}$, os deputados com vínculos a associações/sindicatos de empresários se sobressaem pela participação em duas, quais sejam: a frente parlamentar das agências reguladoras e a frente parlamentar da habitação e desenvolvimento urbano. A primeira, a frente parlamentar das agências reguladoras, tem a adesão de quase metade $(47,37 \%$ contra $20,66 \%$ para o conjunto do universo) dos deputados com vínculos em associações/sindicatos de empresários. Como parece evidente, trata-se de uma frente parlamentar fortemente centrada na defesa da regulamentação do mercado econômico e de suas relações com as políticas governamentais. No caso da frente parlamentar da habitação e desenvolvimento urbano, a participação dos deputados vinculados a associações/sindicatos de empresários também se aproxima da metade destes (43,86\% dos vinculados a associações/sindicatos de empresários e $23,14 \%$ do conjunto dos deputados). Nesse caso, pode-se dar a impressão da inexistência de relações mais estreitas com o universo empresarial. Porém, trata-se de uma frente parlamentar que se opõe, particularmente, àquela da reforma urbana e de outras que representam posições de interesses organizados e movimentos sociais mais à "esquerda" no espectro político.

Algo semelhante ocorre com a frente parlamentar de defesa da produção, emprego e desenvolvimento, com a adesão de quase um terço $(29,8 \%)$ dos deputados com vínculos em associações/sindicatos de empresários e de apenas 15,1\% do conjunto dos deputados.

No extremo oposto do espectro político, ao tomar os deputados vinculados a associações/sindicatos de professores (de todos os níveis), o primeiro aspecto que se ressalta é relativo à própria autoclassificação profissional, sendo que menos de três quartos $(70,4 \%)$ se classificam como professores. Do restante, uma
11. As informações relativas às frentes parlamentares foram extraídas de um trabalho específico sobre o conjunto das mesmas na legislatura de 2003 a 2007, ainda inédito. Nesse trabalho, além do grau de adesão ou de distanciamento dos deputados relativamente ao conjunto das frentes parlamentares existentes e a cada uma em particular, foi examinada sua associação com os indicadores do trajeto social e político. 
parte considerável $(11,1 \%)$ se define como advogado no que tange à profissão e outro tanto $(11,1 \%)$ como outros profissionais com titulação universitária. Esse constitui, portanto, um dos casos de maior diferença entre as categorias profissionais de autoclassificação e os respectivos trajetos ocupacionais e de engajamento associativo/sindical.

Mais da metade (59,3\% contra $24,6 \%$ do conjunto do universo) dos vinculados a associações/sindicatos de professores já ocupou cargos em âmbito nacional na respectiva organização e o restante em nível regional $(7,4 \%)$, municipal $(3,7 \%)$ ou em organizações não hierarquizadas em bases territoriais $(14,8 \%)$, restando, portanto, apenas uma pequena parte $(7,4 \%)$ dos que se declaram como meros sócios ou membros.

No que tange ao montante do patrimônio, os deputados vinculados a associações/sindicatos de professores mantêm uma forte associação com determinadas faixas, que, apesar da relativamente grande dispersão, podem ser consideradas como, em geral, baixas ou médias. As maiores concentrações ocorrem, naquela de dez a cinquenta mil dólares, com uma terça parte $(33,3 \%$ contra $8,7 \%$ do conjunto do universo) e, naquela de cinquenta a cem mil dólares ( $18,5 \%$ contra $7,3 \%$ do conjunto do universo), além de uma quarta parte $(25,9 \%$ contra $34,3 \%$ do conjunto do universo) na faixa de cem a quinhentos mil dólares e pouco mais de uma décima parte $(11,1 \%)$ naquela de quinhentos mil a um miIhão de dólares. Assim como não há ocorrência nas faixas acima de um milhão de dólares (13,0\% do conjunto do universo) também não há naquelas abaixo de dez mil dólares.

Quanto às principais ocupações no decorrer da carreira profissional, os deputados vinculados a associações/sindicatos de professores mantêm uma forte associação, em primeiro lugar, com aqueles cujo trajeto consiste no exercício do magistério superior e na ocupação de cargos públicos por indicação (40,7\%). A seguir se destacam aqueles para os quais essa composição é formada pelo magistério no ensino elementar e secundário e pela ocupação de cargos públicos por indicação e/ou eletivos $(37,0 \%)$, além dos que foram principalmente servidores/funcionários públicos e dirigentes sindicais (11,1\%).

Os deputados vinculados a associações/sindicatos de professores constituem o único agrupamento mais diretamente associado às chamadas ciências humanas, sendo que não muito menos da metade $(40,7 \%$ contra $9,8 \%$ para o conjunto do universo) é portadora de algum título nessa área, além de pouco mais de uma décima parte $(11,1 \%$ contra $28,8 \%$ do conjunto do universo) em direito, outro tanto em medicina (14,8\% contra $13,1 \%$ do conjunto do universo) e o restante distribuído por uma diversidade de outros cursos. 
A filiação partidária constitui outra característica muito específica dos deputados vinculados a associações/sindicatos de professores, particularmente pela altíssima concentração num único partido, o $\mathrm{PT}$, com quase quatro quintos $(77,8 \%$ contra $15,9 \%$ do conjunto do universo). O restante se distribui entre o PSDB $(11,1 \%), \operatorname{PMDB}(7,4 \%)$ e PCdoB $(3,7 \%)$.

Visto que os filiados ao PT são os apresentam menos mudanças de partido em seu trajeto e como ocorre uma forte concentração nesse partido, esse conjunto de deputados constitui um dos com maior proporção entre os sem troca de partido. Mais da metade $(63,0 \%)$ dos vinculados a associações/sindicatos de professores e menos de uma terça parte $(31,2 \%)$ do conjunto dos deputados considerados tem apenas uma filiação partidária em seu trajeto. Praticamente todo o restante $(33,3 \%$ ) daqueles (e $24,3 \%$ do conjunto dos deputados) têm duas filiações.

Além da posição bastante específica relativamente à filiação partidária, os deputados vinculados a associações/sindicatos de professores se caracterizam, também, por um outro indicador de posição política, qual seja, a participação em frentes parlamentares, que marcam determinadas posições frente a uma série de questões político-ideológicas. Algumas dessas frentes parlamentares apresentam um forte caráter de catalizadoras de interesses organizados em nome de determinadas empresas e de vanguardas morais. Outras se caracterizam, particularmente, por suas relações com o engajamento sindical ou associativo ou, ainda, com outras "causas" político-ideológicas, como o ecologismo. Ou seja, do mesmo modo que ocorre uma relativamente forte homologia entre as posições no espaço político e a participação em determinadas frentes parlamentares, os deputados vinculados associativamente a algumas categorias se sobressaem tanto pela posição nesse espaço, como pela maior valorização da participação nessas frentes parlamentares. Os vinculados às associações/sindicatos de professores, seguidos pelos cuja base inclui o sindicalismo de trabalhadores em geral ocupam uma posição extrema, tanto no que tange à posição específica no espaço político como pelas frentes parlamentares de adesão.

Uma das frentes parlamentares de maior participação dos deputados vinculados a associações/sindicatos de professores, ainda se restringindo à legislatura de 2003/2007, é aquela da defesa da energia de fontes renováveis, ou seja, relacionada com determinadas bandeiras de luta e interesses ecologistas. Enquanto pouco mais de uma terça parte $(37,4 \%)$ do conjunto dos deputados do período integrava essa frente parlamentar, essa proporção era de quase nove décimos (89,5\%) para aqueles vinculados a associações/sindicatos de professores. Algo semelhante ocorre com uma outra frente parlamentar com forte apelo ecologista, mas também relacionada com a agricultura familiar, a da defesa da 
aquicultura e pesca, com a adesão formal de menos de uma terça parte $(31,4 \%)$ do conjunto dos deputados da legislatura e bem mais da metade $(68,4 \%)$ daqueles vinculados a associações/sindicatos de professores.

Algo semelhante ocorre com frentes parlamentares de defesa de determinado nacionalismo ou de mobilização contra o endividamento decorrente de empréstimos internacionais, como aquela da defesa do financiamento público e da soberania nacional. A base dessa frente parlamentar constitui um conjunto de organizações sindicais vinculadas a partidos de esquerda e conta com a adesão quatro vezes superior ( $42,1 \%$ contra $10,5 \%$ do conjunto do universo) dos deputados vinculados a associações/sindicatos de professores. O mesmo ocorre com uma série de outras frentes parlamentares, tais como: a da defesa da livre expressão sexual (com a adesão de $47,4 \%$ dos deputados vinculados a associações/sindicatos de professores e $15,5 \%$ do conjunto do universo), da defesa de políticas públicas para a juventude $(52,4 \%$ contra $21,5 \%$ do conjunto do universo), de combate à corrupção (57,9\% contra $23,1 \%$ do conjunto do universo) e, por fim, uma frente parlamentar aparentemente de forte apelo corporativo, a da universidade pública e gratuita (com a adesão de 36,8\% dos deputados com vínculos com associações/sindicatos de professores e $11,6 \%$ do conjunto do universo), que está baseada num segmento específico do sindicalismo de professores de ensino superior.

Quanto aos deputados com vínculos com associações/sindicatos de trabalhadores urbanos, rurais e de funcionários públicos, apesar da sua proximidade com a posição daqueles das associações/sindicatos de professores em muitos aspectos, uma primeira característica própria que se destaca é sua composição relativamente à profissão declarada. A principal concentração ocorre entre os incluídos no agrupamento dos trabalhadores e técnicos do comércio e prestação de serviços, com quase uma quinta parte $(19,1 \%)$, mas com forte dispersão entre outras categorias. Dentre essas, se destacam a dos trabalhadores de diferentes setores $(15,3 \%)$, outros profissionais com titulação universitária que não médicos e advogados (16,8\%), advogados (14,5\%) e funcionários públicos em geral $(13,0 \%)$, dentre outras em menor grau.

No que tange às principais ocupações na carreira profissional, as associações mais fortes dos vinculados a esse tipo de associações/sindicatos ocorrem com aqueles cujo trajeto é composto pela condição de servidor/administrador público e exercício de cargos públicos por indicação (18,6\%), seguidos pelos que, além de funcionários/servidores públicos, também foram dirigentes sindicais $(14,7 \%)$, pelos cujo trajeto se resume basicamente na ocupação de cargos públicos por indicação $(5,4 \%)$ e, por fim, pelo exercício de cargos eletivos $(4,7 \%)$.

Quanto ao montante do patrimônio econômico, quase uma terça parte (30,3\% 
contra $34,3 \%$ do conjunto do universo) dos vinculados a esse tipo de associações/sindicatos situa-se na faixa de cem a quinhentos mil dólares. A maior parte do restante está incluída nas faixas imediatamente abaixo, ou seja, naquela de cinquenta mil a cem mil dólares $(16,7 \%$ contra $7,3 \%$ do conjunto do universo) e de dez mil a cinquenta mil dólares $(13,6 \%)$. Como parece evidente, se por um lado isso se indica, para o montante do patrimônio, em geral, abaixo da média do conjunto dos deputados, por outro, se trata de faixas relativamente distantes do piso.

Relativamente à titulação escolar, uma das associações mais fortes desses deputados com vínculos com associações/sindicatos de trabalhadores urbanos, rurais e de funcionários públicos é com os sem curso universitário, com mais de uma quarta parte $(26,4 \%$ contra $16,11 \%$ do conjunto do universo). Os demais são formados, principalmente, em direito $(22,4 \%$ contra $28,8 \%$ do conjunto do universo), ou em algum tipo de curso de engenharia (14,4\%). Portanto, no que tange à titulação escolar, os deputados vinculados a esse tipo de associações/ sindicatos, além do tipo de curso realizado, se sobressaem também pelo menor grau de escolarização. Dentre aqueles sem curso universitário completo, uma parte significativamente superior à média $(15,4 \%$ contra $8,3 \%$ do conjunto do universo) tem até o 2 o grau e uma outra parte também significativa $(14,6 \%)$ tem algum tipo de curso superior incompleto.

A filiação partidária constitui uma das principais semelhanças com os deputados vinculados a associações/sindicatos de professores, o que os distancia daqueles das associações/sindicatos de empresários e, em menor grau, de médicos, advogados, engenheiros e assemelhados. Mais da metade (50,4\% contra $15,9 \%$ do conjunto do universo) é filiada ao PT. O restante se distribui entre vários partidos, diferentemente dos vinculados a associações/sindicatos de professores. Os principais desses partidos são o PMDB $(15,5 \%)$, PCdoB $(3,8)$, PDT $(3,8 \%)$, PL $(3,8 \%)$ e PSB $(5,3 \%)$.

Também a exemplo dos deputados vinculados a associações/sindicatos de professores, esse padrão de filiação partidária tem efeitos na menor quantidade de mudanças de partido. Bem mais da metade $(60,3 \%$ contra $31,2 \%$ do conjunto do universo) tem somente uma filiação no respectivo trajeto e a maior parte do restante $(19,8 \%)$ tem duas filiações, restando, portanto, apenas uma pequena parte com mais de duas filiações.

Uma outra característica que marca particularmente os deputados vinculados a associações/sindicatos de trabalhadores urbanos, rurais e de funcionários públicos é a menor proporção daqueles com parentes que também são políticos. Quase nove décimos (87,1\% contra $72,5 \%$ do conjunto do universo) não tem registro de parente político (que tenha ocupado cargo público eletivo), 
12. Diversamente do conjunto dos demais indicadores, cujas informações são solicitadas formal e sistematicamente a todos os deputados, aquelas relativas à eventual existência de algum parente também político foram coletadas no conjunto das fontes esparsas disponíveis, todas de caráter parcial. Portanto, não se trata de informações exaustivas, mas meramente indicativas. Além disso, abrangem somente os ocupantes de cargos públicos eletivos, excluindo, portanto, aqueles por indicação. proporção da qual somente os deputados vinculados a associações/sindicatos de professores $(85,2 \%)$ se aproximam. No extremo oposto, de maior proporção daqueles com algum registro ${ }^{12}$ de parente político, se destacam os sem qualquer vínculo com associações/sindicatos $(66,6 \%$ contra $72,5 \%$ do conjunto do universo sem registro) e aqueles ligados apenas a organizações do movimento estudantil $(63,8 \%)$.

Por fim, quanto ao tipo de participação na respectiva organização, mais de uma quinta parte $(21,4 \%$ contra $9,8 \%$ do conjunto do universo) dos deputados com vínculos em associações/sindicatos de trabalhadores urbanos, rurais e de funcionários públicos é constituída por aqueles que já ocuparam cargos de direção em âmbito nacional ( $51,1 \%$ contra $24,6 \%$ do conjunto do universo). A maior parte do restante já ocupou cargos de direção em outros níveis, seja regional $(13,0 \%)$ ou municipal $(9,2 \%)$, sendo que apenas uma pequena parte $(5,3 \%)$ se declara como apenas membro ou sócio.

Além da filiação partidária, um outro indicador relativo à posição política, ou seja, a adesão a frentes parlamentares, aproxima os deputados com vínculos com associações/sindicatos de trabalhadores urbanos, rurais e de funcionários públicos daqueles das associações/sindicatos de professores. A exemplo desses últimos, os deputados vinculados a associações/sindicatos de trabalhadores urbanos, rurais e de funcionários públicos participam de modo mais intenso nas frentes parlamentares que seguem: de combate à corrupção, da livre expressão sexual, da defesa da energia de fontes renováveis, da defesa do financiamento público e da soberania nacional, da defesa da universidade pública e gratuita e, por fim, da aquicultura e pesca.

No que tange à frente parlamentar de combate à corrupção, que conta com a adesão de menos de uma quarta parte do conjunto dos deputados $(23,1 \%)$, quase metade $(47,4 \%)$ dos deputados vinculados a associações/sindicatos de trabalhadores urbanos, rurais e de funcionários públicos participam da mesma. De modo semelhante, a frente parlamentar de defesa da livre expressão sexual conta com a adesão de uma quantidade relativamente pequena (15,5\%) do conjunto dos deputados, mas inclui mais de uma terça parte $(36,8 \%)$ desses últimos. No caso da frente parlamentar da defesa da universidade pública e gratuita essa diferença de proporções entre aqueles vinculados a associações/sindicatos de trabalhadores urbanos, rurais e de funcionários públicos (26,3\% tendo aderido à mesma) e o conjunto dos deputados (11,6\% de aderentes) é ainda mais forte. Por fim, a frente parlamentar da aquicultura e pesca conta com a adesão de mais da metade $(50,9 \%)$ dos deputados vinculados a associações/sindicatos de trabalhadores urbanos, rurais e de funcionários públicos e menos de uma terça parte $(31,4 \%)$ do conjunto dos deputados. 
Como se pode ver, em geral, se trata de frentes parlamentares com forte caráter de politização, não apenas no sentido geral de definir a pauta dos problemas em questão como referidos à ordem política, como, também, da utilização de recursos culturais, institucionais e financeiros da esfera estatal para a legitimação e implementação de ações públicas favoráveis a determinadas questões socialmente já constituídas, com forte associação ao sindicalismo, mas também com determinadas "empresas morais" e grupos de interesse. Algumas dessas questões estão mais diretamente vinculadas a determinadas vanguardas morais e culturais, como é o caso, por exemplo, daquela da livre expressão sexual. Outras estão mais diretamente associadas a lutas de posições no interior do espaço sindical, já previamente constituídas, como aquela da defesa do financiamento público e da soberania e, de certa maneira, aquela da defesa da universidade pública e gratuita, com forte ligação com um setor específico do sindicalismo de professores de ensino superior. Por fim, novas bandeiras de luta ideológica em voga, como as baseadas em causas e organizações vinculadas ao ecologismo, que podem estar presentes em frentes parlamentares como a da defesa da energia de fontes renováveis e, inclusive, da aquicultura e pesca, em interação com outras "causas" e grupos de interesse.

Os deputados vinculados a associações/sindicatos de médicos, advogados, engenheiros e assemelhados, no que tange à profissão declarada, são constituídos, particularmente, por médicos, com mais de uma terça pare $(35,4 \%$ contra $11,1 \%$ do conjunto do universo). Um segundo conjunto, equivalente a uma quinta parte $(20,1 \%)$ é formado por advogados. Portanto, mais da metade dos deputados com algum vínculo com esse tipo de associação/sindicato é composta de médicos e advogados. O restante é constituído por uma variedade de categorias profissionais com formação universitária.

Mais ainda que os deputados vinculados a outras modalidades de associações/sindicatos, esses dos médicos, advogados, engenheiros e assemelhados, se constituem, particularmente, de dirigentes da respectiva organização. Uma proporção acima da média ( $13,6 \%$ contra $9,8 \%$ do conjunto do universo) foi dirigente em âmbito nacional e quase metade $(43,5 \%$ contra $24,6 \%$ do conjunto do universo) ocupou cargo de direção em nível estadual ou, ainda, municipal $(11,6 \%)$ ou regional $(10,9 \%)$. Isso, no entanto, não elimina uma parte significativa, de quase um quinto $(18,4 \%$ contra $4,9 \%$ do conjunto do universo) que se declara apenas como membro ou sócio.

Quanto às ocupações no decorrer da carreira profissional, a maior concentração desses vinculados a associações/sindicatos de médicos, advogados, engenheiros e assemelhados é daqueles cujo trajeto é composto pelo exercício da medicina, em alguma de suas diferentes modalidades, e a ocupação de cargos públicos por indicação e/ou eletivos. Esse padrão de 
trajeto profissional abrange uma terça parte $(32,4 \%)$. Uma segunda parte significativa tem seu trajeto profissional composto, principalmente, pelo exercício do magistério superior e ocupação de cargos públicos por indicação e/ou eletivos $(11,7 \%)$. Uma proporção aproximada $(11,7 \%)$ tem no exercício da advocacia e a ocupação de cargos públicos por indicação e eletivos o principal das ocupações no trajeto profissional, e outro tanto $(10,3 \%)$ como servidor/administrador público e exercício de cargos por indicação. Uma parte menor $(5,5 \%)$ tem o trajeto composto pela administração/propriedade de empresas privadas e ocupação de cargos públicos por indicação e eletivos. Por fim, há uma quantidade significativa daqueles cujo trajeto consiste basicamente na ocupação de cargos públicos, por indicação ou eletivos (6,1\%). Portanto, como parece ficar evidente, apesar da vinculação às associações/sindicatos, em geral com uma carreira de dirigente na respectiva organização, a quase totalidade desses deputados desenvolveu também uma carreira política, que inclui a ocupação de cargos públicos, por indicação ou por eleição, de modo simultâneo ou sucessivo.

Como se trata predominantemente de médicos e advogados, no que tange à titulação universitária, mais de uma terça parte $(37,5 \%$ contra $13,1 \%$ do conjunto do universo) é constituída de formados em medicina, seguida pelos que cursaram direito, com mais da quarta parte $(25,7 \%)$. Do restante, quase uma décima parte $(9,7 \%)$ é composta por aqueles das engenharias, outro tanto pelos que cursaram agronomia $(5,6 \%)$ e economia $(5,6 \%)$, dentre outros em menor grau.

Como se trata de um conjunto fortemente associado à alta titulação escolar, entre os deputados vinculados a associações/sindicatos de médicos, advogados, engenheiros e assemelhados, além da graduação universitária, uma boa parte também realizou algum curso de pós-graduação. Uma décima parte $(10,1 \%$ contra $2,8 \%$ do conjunto do universo) é portadora de título de doutorado, uma parte semelhante $(12,2 \%$ contra $2,8 \%$ do conjunto do universo) de mestrado, quase uma terça parte $(31,7 \%$ contra $16,7 \%$ do conjunto do universo) de especialização e, por fim, uma outra parte significativa $(10,8 \%)$ realizou algum estágio de atualização ou algo assemelhado.

Quanto à filiação partidária, diversamente daqueles vinculados a associações/ sindicatos de empresários ou então de trabalhadores urbanos, rurais e de funcionários públicos, que ocupam posições polares, ocorre uma forte concentração em alguns poucos partidos, nesse caso há uma grande dispersão, abrangendo todo o espectro das posições políticas. Mesmo as leves concentrações que ocorrem em alguns partidos não se distanciam muito da média do conjunto. Dentre essas pequenas concentrações, se destaca aquela dos filiados no PT (18,5\% contra $15,9 \%$ do conjunto do universo), PMBD $(15,8 \%$ contra $16,9 \%$ do conjunto do universo), PFL/DEM (11,0\% contra $13,0 \%$ do conjunto do universo), PSDB ( $12,3 \%$ contra $13,9 \%$ do conjunto do universo), PSB (6,8\% contra $5,5 \%$ 
do conjunto do universo), PDT (6,8\% contra $4,4 \%$ do conjunto do universo), PP ( $4,8 \%$ contra $6,3 \%$ do conjunto do universo), PTB $(6,2 \%$ contra $7,2 \%$ do conjunto do universo) e o restante se distribui na série de pequenos partidos.

Como consequência dessa forte dispersão na distribuição dos partidos de filiação, apesar de os partidos apresentarem padrões distintos de durações ou de troca de filiação, no caso dos deputados vinculados a associações/sindicatos de médicos, advogados, engenheiros e assemelhados, não chega a haver alguma tendência mais definida quanto ao número de filiações. Embora fique evidente uma relativamente menor quantidade de filiações e, portanto, de troca de partido, em quase todas as faixas há proximidade da média do conjunto do deputados em consideração. Pouco mais de uma terça parte (35,6\% contra 31,2\% do conjunto do universo) tem apenas uma filiação partidária e a maior parte do restante situa-se nas faixas de duas $(24,0)$, três $(19,9 \%)$ e quatro filiações $(10,3 \%)$ e os demais numa proporção um tanto menor que a média do conjunto, nas faixas acima.

Diversamente dos deputados vinculados a outros tipos de associações/sindicatos, médicos, advogados, engenheiros e assemelhados não estão diretamente associados a qualquer frente parlamentar específica. Isso se aplica tanto à adesão, sem qualquer associação mais significativa com alguma, como também, à não participação ou ao distanciamento.

Representação de interesses e representação política

A forte associação na participação em determinadas associações/sindicatos e o cargo de deputado federal pode ser mais bem qualificada ao confrontar os índices de sindicalização das principais categorias ocupacionais (numa amostra estatisticamente representativa, conforme a PNAD - Pesquisa Nacional Por Amostra de Domicílios, IBGE, 2006). Isso indica que se, por um lado, há um processo de reconversão de recursos associativos/sindicais em possibilidades eleitorais e políticas, por outro, não são todas as categorias profissionais ou ocupacionais que dispõem de condições de formação desses recursos. Dito de outro modo, os próprios recursos associativo/sindicais dependem de determinadas condições e modalidades de inserção profissional e social.

Em de 2005, quase uma quinta parte do conjunto da população (com dez anos ou mais de idade) estava associada a algum sindicato. Porém, essa proporção é extremamente variável e dependente da categoria ocupacional e, por extensão, do grau de escolarização, do setor da atividade, dentre outros condicionantes. No extremo do pólo das categorias ocupacionais, com índice mais alto de sindicalização, destacam-se os profissionais policientíficos $(61,2 \%$ contra $18,4 \%$ 
13. Como consequência das sucessivas mudanças na legislação pertinente, no Brasil, existem associações profissionais e sindicatos que, em geral, atuam de modo complementar, apesar das respectivas especificidades. do conjunto do universo), os professores de ensino superior $(49,3 \%)$, professores de 1 ㅇ e 2 o grau $(44,4 \%)$, profissionais das ciências jurídicas $(26,3 \%)$, produtores na exploração agropecuária, pesca e extrativista florestal $(44,5 \%)$, profissionais das ciências exatas (33,7\%), profissionais das ciências biológicas, da saúde e afins $(40,4 \%)$, membros superiores e diretores do poder público $(29,5 \%)$, dentre outras. No extremo oposto, da menor sindicalização, se destacam categorias ou agrupamentos como os comunicadores, artistas e religiosos (9,5\% contra $18,4 \%$ do conjunto do universo), trabalhadores de serviços e do comércio $(10,6 \%)$, trabalhadores da indústria de diferentes setores $(16,4 \%)$ e as ocupações mal definidas ou não especificadas (5,0\%). Além dos militares, com uma situação e regulamentação específicas, há uma forte associação entre o grau de escolarização e, também, de formalização das relações de trabalho, dentre outros indicadores de recursos sociais, e o grau de sindicalização. Apesar de os dados disponíveis para o conjunto da população abrangerem somente a filiação em sindicatos, excluindo, portanto, outras associações profissionais ${ }^{13}$ incluídas no exame dos trajetos dos deputados, há uma homologia muito forte entre esses dois universos, ou seja, o conjunto dos deputados estudados e a amostra da população brasileira, relativamente a esse ponto.

Como mencionado, ocorre uma forte associação entre o grau da titulação escolar mais alta e o maior índice de sindicalização, embora essa relação não seja linear. No pólo de maior sindicalização, destacam-se aqueles com curso de mestrado ou doutorado, com quase metade $(46,7 \%$ contra $18,4 \%$ do conjunto do universo). A seguir, se destacam aqueles com algum curso superior, com uma terça parte de sindicalizados (33,2\%). Por outro lado, também se destacam aqueles que têm apenas cursos de alfabetização de adultos $(32,0 \%)$, que atingem praticamente a mesma proporção dos anteriores. No extremo dos menores índices de sindicalização destacam-se aqueles com apenas o ensino fundamental $(12,7 \%)$.

Quanto à posição no trabalho principal, os funcionários públicos são os com maior índice de sindicalização (40,9\% contra $18,4 \%$ do conjunto do universo), seguidos pelos empregados com carteira assinada $(28,4 \%)$. No extremo oposto, se destacam categorias como os trabalhadores domésticos (2,2\%), trabalhadores por conta própria $(4,3 \%)$, trabalhadores na construção para o próprio uso $(10,0 \%)$, dentre outros. Ou seja, se trata de categorias com relações de trabalho menos formalizadas e com menores garantias sociais.

Quanto ao rendimento, também ocorre um grau de associação muito forte com os índices de sindicalização. Tomando, através do rendimento do trabalho principal, todas as faixas mais altas de rendimento também são aquelas com maior índice de sindicalização, particularmente, sendo que as acima de setecentos dólares mensais variam de $36,5 \%$ a $44,0 \%$ de sindicalizados. No extremo oposto 
se destaca a faixa mais baixa, de até cem dólares (com apenas 10,5\% de sindicalizados) e as imediatamente acima.

\section{Considerações Finais}

Apesar das bases e os princípios de legitimação das atividades políticas enquanto tais e das respectivas posições nesse espaço constituírem um dos principais problemas para a compreensão dos processos de recrutamento dos políticos, a quantidade de estudos empíricos diretamente dedicados a esse tipo de questão não são equivalentes às discussões mais gerais. Nos países centrais, ocorre uma tendência crescente no sentido de tomar como central, no estudo do recrutamento de elites políticas, a substituição dos "notáveis locais" pelos "políticos profissionais". Como principal atributo desse "político profissional", além da continuidade da ocupação de cargos públicos, é destacado o maior grau de escolarização, em geral em escolas de "elite", e o domínio de determinadas "tecnologias" vinculadas à gestão pública ${ }^{14}$. Porém, nem sempre são tomados como centrais os efeitos das novas condições de formulação e organização de interesses, que também podem estar associados a essas "tecnologias" e seus efeitos não apenas no recrutamento, mas também na legitimação das atividades políticas. Em situações como aquelas da França do período recente, essa legitimação estaria centrada nas atividades partidárias (GAXIE \& OFFERLÉ, 1985). Sendo assim, tanto a legitimação das atividades e posições políticas, como a reconversão de problemas sociais em formulações políticas, estão centradas no engajamento e militância partidária. Consequentemente, o engajamento e militância associativa mantêm uma posição de relativa externalidade ou, então, de estrita subordinação frente à militância partidária. Por sua vez, como já mencionado, o chamado modelo "pluralista", se por um lado, destaca a importância da organização e defesa de interesses, por outro, a define como algo anterior às atividades políticas, que ficariam a cargo dos partidos, embora nesse caso, preferencialmente, sem maiores confrontos ideológicos (ALMOND, 1958).

Como os dados apresentados evidenciam, nas condições estudadas, as atividades associativas/sindicais e partidárias, mais que alguma dicotomia, apresentam diferentes padrões de interação, complementação e afinidades eletivas, o que não significa que sejam redutíveis. Essa complementaridade e afinidades eletivas, no entanto, envolvem diferentes níveis e lógicas sociais e um mesmo "empresário" da política pode apresentar diferentes recursos políticos, mais ou menos articulados. É essa possibilidade de diferentes formulações e discursos políticos que torna possível a deputados vinculados a alguma associação ou sindicato não se apresentarem eleitoralmente em nome apenas da categoria profissional ou ocupacional representada pela organização em pauta.
14. Ver, particularmente, Best \& Gaxie (2000, p. 129) 
De modo semelhante, os processos de politização, no sentido de atribuir um significado político a determinado tema ou problema, também abarca diferentes significados conforme a "empresa" e interesses aos quais estão associados.

Abstract: This paper results from an analysis of the associative engagement for the recruitment and legitimization of political elites. The different modalities of the relations with unions and associations are examined considering the federal deputies who have taken their positions from 1999 to 2007. These relations are compared to other conditions and resources such as those related to schooling degree, the amount of economical property, partisan affiliation and the number of switching between political parties. According to one of the general conclusions, there is a strong homology between the distribution of federal deputies according to their associative relation, both in partisan politics and in the political environment. However, this is not simply a dichotomy between activities, associative and political-partisan scopes, but rather different patterns of complementarity, elective affinities, ambivalences and detachment, and therefore different patterns of resources and modalities that could be used in different conditions and processes for politization.

Keywords: Political Representation, Associative Capital, Political Elites, Political Commitment and Militancy, Groups of Interest

\section{Referências Bibliográficas}

Almond, G. A. (1998) "Research note; Comparative study of intereset groups and the political process". The American Political Science Review, Washington. vol. 53 , n. 1 , mar.

Badie, B. (1994) Le Développement Politique. 5e. Edition. Paris: Economica.

Best, H. \& Cotta, M. (eds.) (2000) Parlamentary Representatives in Europe 18482000. Legislative recruitment and careers in eleven european countries. Oxford: Oxford University Press

Bourdieu, P. (2000) “Formes d'action politique et modes d'existence des grupes" in ___ Propos Sur le Champ Politique. Lyon: Presses Universitaires de Lyon.

Best, H. \& Gaxie, D. (2000) "Detours to modernity: long-term trends of parliamentary recruitment in Republican France since 1863", in H. Best \& M. Cotta (eds.), Parlamentary Representatives in Europe 1848-2000. Legislative recruitment and careers in eleven european countries. Oxford: Oxford University Press 
Bourdieu, P. (1984) "La délégation et le fétichisme politique". Actes de la Recherche en Sciences Sociales, n. 51/53, juin.

Combes, H. (2004) De la Politique Contestataire à la Fabrique Partisane; Le cas du Parti de la révolution démocratique au Mexique. Tese de Doutorado, Université Paris III.

Coradini, O. L. (2007) "Associative/Union Commitment and the Recruitment of political elites: recent trends in Brazil". International Journal of Contemporary Sociology, vol. 44, n. 2: 201-227.

Daloz, J. P. (2003) "Political representation and the Connection Between Symbols of Distinction and Symbols of Likeness". Paper prepared for ECPR Workshop on Political Representation, Edinburgh, mar.

Gaxie, D. \& Offerlé, M. (1985) "Les militants syndicaux et associatifs au pouvoir? Capital social collectif et carrière politique" in P. Birnbaum (dir.) Les Élites Socialistes au Pouvoir; Les Dirigeants Socialistes Face à Etat: 1981-1995. Paris: Presses Universitaires de France.

Goldstone, J. A. (ed.) (2003) State, Parties, and Social Movements. Cambridge: Cambridge University Press.

IBGE - Instituto Brasileiro de Geografia e Estatística (2006) Pesquisa Nacional Por Amostra de Domicílios. Microdados. Rio de Janeiro: IBGE. Compact Disc.

Jenkins, J. G. \& Kladermans, B. (eds.) (1995) The Politics of Social Protest: Comparative perspectives on State and Social Movements. London: University College of London.

Keeler, J. T. S. (1985) "Situationg France on the pluralism-corporativism continuum; A critique of and alternative in Wilson perspective". Comparative Politics, jan: 229-249.

Lagroye, J. (2003) "Les processus de politisation" in La Politisation. Paris: Belin.

Lagroye, J., François, B. \& Sawicki, F. (2002) Sociologie Politique. 4a. ed. Paris: Presses de Sciences Po et Dalloz.

Manin, B. (1995) Principes du Gouvernement Représentatif. Paris: Calmann Levy.

Wilson, F. L. (1982) "Alternative models of interest intermediation: the case of France". British Journal of Political Science, vol. 12, jan: 173-200. 
Wilson, F. L. (1983) "Les groupes d'interêt sous la cinquième Republique; Test de trois modeles théoriques de l'interaction entre groupes et gouvernement". Revue Française de Science Politique, vol. 33, n. 2, avril. 